\title{
PROJETO DE PRODUTO UTILIZANDO PROCESSOS DE MODELAGEM PARAMÉTRICA, PROTOTIPAGEM E FABRICAÇÃO DIGITAL
}

\author{
Felipe Schneider Viaro; \\ Universidade Federal do Rio Grande do Sul \\ felipe.viaro@ufrgs.br \\ Rogélio Pinheiro; \\ Universidade Federal do Rio Grande do Sul \\ rogelio.pinheiro@gmail.com \\ Régio Pierre da Silva; \\ Universidade Federal do Rio Grande do Sul \\ regio@ufrgs.br \\ Fábio Gonçalves Teixeira; \\ Universidade Federal do Rio Grande do Sul \\ fabiogt@ufrgs.br \\ Underléa Miotto Bruscato; \\ Universidade Federal do Rio Grande do Sul \\ underlea.bruscato@ufrgs.br
}

\begin{abstract}
Resumo: Este artigo apresenta o processo de redesign de um utensílio polimérico considerando principalmente os processos de modelagem paramétrica, prototipagem e fabricação digital. Para o desenvolvimento do conceito, foram utilizadas as técnicas de análise do briefing, do produto e de similares, assim como a modelagem digital parametrizada. A fim de avaliar a solução proposta, realizaram-se testes de prototipagem: com o protótipo digital verificou-se a adequação do modelo $3 \mathrm{D}$ em relação ao tamanho do produto e ao portfólio da empresa; com o protótipo físico, verificaram-se as propriedades físicas do produto e suas relações com o usuário. Como resultado deste processo observou-se que o software Grasshopper $^{\circledR}$ se mostrou uma ferramenta adequada para gerar alternativas de projeto a partir de uma concepção definida, pois permite a variação de determinados parâmetros como ângulos, distâncias e espessuras. As diferentes técnicas de prototipagem se mostraram úteis no desenvolvimento de projeto de produtos.
\end{abstract}

Palavras-chave: design de produto, protótipo, prototipagem, fabricação digital, modelagem paramétrica. 


\begin{abstract}
This article presents the redesign process of a polymeric utensil with emphasis on parametric modeling, prototyping and digital manufacturing. For the concept development, a technical analysis of the briefing, the product and competitors was made. Also, parameterized digital modeling was used. In order to evaluate the proposed solution, there were prototyping tests: with the digital one, it was verified the adequacy of the model in relation to the size of the product and the company's portfolio; with the physical prototype there were analyzed the physical properties of the product and relations with the user. It was observed that the Grasshopper ${ }^{\circledR}$ software proved to be a suitable tool to generate design alternatives from a set design, allowing variation of certain parameters such as angles, distances and thicknesses. The different prototyping techniques have proven useful in the development of product design.
\end{abstract}

Keywords: industrial design, prototype, prototyping, digital manufacturing, parametric modeling.

\title{
1 INTRODUÇÃO
}

A fabricação digital consiste na utilização de técnicas de produção de produtos, objetos e protótipos a partir de modelos virtuais. Entre as vantagens desse processo destacam-se a rapidez e precisão na geração das propriedades físicas e geométricas dos modelos virtuais, além de possibilitar a produção em massa de produtos personalizados (ORCIUOLI, 2013).

Complementares a isso, as técnicas de modelagem e prototipagem digital auxiliam a reduzir o tempo de lançamento de um produto por meio de simulações e correções rápidas no projeto (ESPINOZA; SCHAFFER, 2004). Estes fatores são determinantes para o sucesso do produto, pois os custos com correções no desenvolvimento do projeto aumentam significativamente na medida em que as etapas do projeto avançam (BACK et al., 2008; HALLGRIMSON, 2012).

Nesse contexto, a modelagem tridimensional paramétrica surge como uma técnica promissora, pois permite gerar inúmeras variações em modelos de produto a partir da manipulação de parâmetros básicos como altura, largura, espessura, quantidade de furos, etc. Particularmente, no caso do design de produtos, a modelagem paramétrica pode ser utilizada desde a etapa de projeto conceitual, após a definição básica das características produto.

As técnicas de prototipagem, que fazem o uso de protótipos físicos e digitais para testar o produto, podem ser utilizadas de maneira complementar ao desenvolvimento do conceito do produto. A prototipagem digital verifica aspectos visuais, comunicacionais, de encaixes e de forças físicas atuantes sobre o produto. A prototipagem física verifica os materiais, o funcionamento e a relação do produto com o usuário.

Considerando os benefícios do uso de métodos de prototipagem digital como auxílio no design de produtos, o objetivo deste trabalho é desenvolver o redesign de um produto com ênfase em processos de prototipagem e fabricação digitais. 0 processo de redesign partiu da análise do briefing e do produto a ser redesenhado, considerando o portfólio de produtos da empresa e seus processos de fabricação. 0 projeto conceitual utilizou o software de modelagem paramétrica Grasshopper ${ }^{\circledR}$. O software permitiu o desenvolvimento de diversas concepções, alterando parâmetros de projeto como altura, angulação e distâncias. 


\section{DESIGN DE PRODUTOS E FABRICAÇÃO DIGITAL}

Estima-se que para gerar um novo produto são necessários 100 conceitos iniciais, que são continuamente refinados na medida em que o projeto se desenvolve. Para gerar essa quantidade de ideias é necessária uma equipe de projeto criativa e, uma das maneiras de se atingir isso, é utilizando as técnicas criativas (BACK et al., 2008).

Ao projetar um produto objetiva-se satisfazer uma determinada população de consumidores, atendendo suas necessidades e expectativas (SLACK, 2007). Para isso, a etapa inicial é o projeto conceitual, em que se que determinam os princípios de solução (PAHL et al., 2005), tendo como objetivo assegurar que o produto irá executar sua função de acordo com a previsão, atendendo os requisitos definidos. As soluções podem ser representadas através de rascunhos, fluxogramas, cálculos, protótipos, entre outros (BOLGENAGEM, 2003).

Segundo Baxter (2006), o objetivo do projeto conceitual, além de satisfazer as exigências do consumidor, deve ser diferenciar o novo produto de outros já existentes. Depois de definido seu conceito, os processos de modelagem tridimensional e fabricação digital agilizam e aperfeiçoam seu desenvolvimento.

De maneira geral, a obtenção de produtos baseados em processos de fabricação digital utilizam sistemas de manufatura aditiva (i.e., prototipagem rápida) ou manufatura restritiva (i.e., usinagem $\mathrm{CNC}$ ). Os sistemas de manufatura aditiva baseiam-se na adição de camadas de um ou mais materiais para obtenção do produto ou objeto final. Na manufatura restritiva o produto final é obtido através da remoção progressiva de material. Nos dois processos descritos, a primeira etapa prevista é a criação de um modelo virtual, desenvolvido em softwares CAD (Computer Aided Design), que permitem a geração e manipulação tridimensional (3D) de formas. Nesses softwares é possível atribuir às peças diferentes tipos de materiais, texturas, volumes e formas para estudar aspectos como encaixes entre peças, montagem e desmontagem do produto, etc (ESPINOZA; SCHAFFER, 2004).

Outra ferramenta utilizada no desenvolvimento de produtos por processos de fabricação digital são os sistemas CAE (Computer Aided Engineering), que permitem simulações de tensões, deformações, análises estruturais por meio de elementos finitos, análise de dilatação térmica, entre outras. Com essa ferramenta as características estruturais do produto são testadas mesmo antes da fabricação de um protótipo físico (ESPINOZA; SCHAFFER, 2004).

Para a produção do produto criado através de CAD ou CAE, pode-se utilizar softwares CAM (Computer Aided Manufacturing). Esses softwares fazem a ponte entre o modelo virtual criado pelo projetista e a máquina que vai trazê-lo ao mundo físico (e.g., a fresadora CNC e a máquina de corte a laser).

\section{PROTOTIPAGEM: O USO DO PROTÓTIPO PARA FINS ESPECÍFICOS}

Os protótipos podem ser utilizados para resolver problemas de projeto e melhorar a compreensão que se tem do produto em desenvolvimento. Dentre outros usos, eles podem auxiliar a geração de ideias, testes com o usuário, comunicação e verificação de requisitos de projeto (HALLGRIMSON, 2012).

$\mathrm{Na}$ geração de ideias, o protótipo deve ser produzido de forma rápida e sem preocupações com detalhes. O objetivo é verificar experimentalmente se uma proposta deve ser seguida, através da exploração de diferentes aspectos do produto físico, como materiais, tecnologias, forma e função. Podem-se construir protótipos em 
paralelo com diferentes enfoques, sendo um para verificar a aparência e outro para o funcionamento, por exemplo (HALLGRIMSON, 2012).

Um dos mais significativos usos do protótipo físico é para realizar testes com o usuário. Assim, podem ser testados requisitos ergonômicos, tais como ajustes, medidas e questões cognitivas. Os protótipos em tamanho real também determinam o fluxo de tarefas e os requisitos de projeto. É necessário explicitar quais testes e tipos de tarefas serão realizados pelo usuário para construir um protótipo adequado (HALLGRIMSON, 2012).

Os protótipos físicos e digitais podem auxiliar na comunicação eficaz entre a equipe de desenvolvimento e os stakeholders (i.e., todos os interessados e envolvidos no processo de projeto). Um ensaio fotográfico com usuários interagindo com o produto em possíveis cenários demonstra como o produto será utilizado e como ele se adequa ao ambiente. Nesse sentido, podem ser destacados os protótipos de aparência, os quais tem alta fidelidade e são usados para comunicar a aparência final do produto. A aparência pode ser construída digitalmente em renderizações computacionais, ou então, fisicamente, por meio de arquivos 3D CAD e de equipamentos de prototipagem rápida (HALLGRIMSON, 2012).

\section{REDESIGN DE PRODUTO}

Este trabalho desenvolve-se a partir de uma proposta de redesign de produto de uma indústria de utensílios poliméricos na cidade de Porto Alegre - RS. O processo de desenvolvimento de produto foi enfatizado na etapa de projeto conceitual, especificamente nas técnicas de modelagem digital paramétrica e de prototipagem digital e física. O projeto se desenvolveu nas seguintes etapas: recebimento do briefing de design; análise do briefing, do produto e do portfólio da empresa; geração e seleção de ideias; modelagem paramétrica; prototipagem digital e física. Este item apresenta o processo de projeto nas etapas descritas.

\subsection{Briefing e análises iniciais}

O briefing transmitido pela empresa em estudo foi desenvolver o redesign do produto Organizador Multiuso Empilhável, pertencente a uma linha de produtos específica. A partir do briefing foram analisados os problemas e as vantagens deste produto para propor melhorias. Os problemas encontrados foram:

- O produto propõe-se a ser multiuso e não é adequado a nenhuma das funções propostas; falta foco na definição do produto;

- A estética do produto faz com que ele seja excluído de ambientes corporativos, como escritórios;

- A falta de ângulos retos na parte interna não permite a acomodação correta de objetos como livros e discos;

- O processo de fabricação determina algumas características estruturais do produto, como a espessura do polímero, que prejudica a ergonomia da pega;

- A comunicação do produto não explicita usos possíveis ao usuário;

- O tamanho, layout e conteúdo da etiqueta-adesiva do produto poderiam ser revistos.

Os pontos positivos destacados do produto são os seguintes:

- A possibilidade de acoplagem que possibilita empilhar mais de uma unidade do produto; 
- O encaixe é adequado para transportar o produto da fábrica até os pontos de venda, diminuindo seu volume total.

Comparando o número de pontos positivos e negativos encontrados no produto, percebem-se possíveis soluções para os problemas de vendas que a marca encontrou. Algumas diretrizes formadas a partir da análise das vantagens e desvantagens foram:

- Sugerir usos específicos para o produto e adequá-lo ao uso em banheiro e área de serviço;

- Prever encaixe entre unidades maiores e menores da mesma linha de produtos;

- Pensar em outras possibilidades de encaixes;

- Analisar a relação do produto com a linha em que ele está inserido e com o portfólio da empresa.

Com a análise realizada, foi decidido que o material usado pela empresa (polipropileno), assim como o processo utilizado (injeção) seriam mantidos para gerar soluções passíveis de serem produzidas. O PP (polipropileno) tem um grau elevado de transparência e suporta cores mais vívidas, quando comparado ao PE (polietileno) por exemplo. O PP é muito utilizado em ambientes como banheiros e cozinhas por ser excepcionalmente inerte e fácil de reciclar (ASHBY, 2011).

O portfólio da empresa foi utilizado com referência para desenvolvimento do projeto, respeitando o estilo do produto, os materiais e cores utilizados, e a proposta da empresa com a linha do produto em questão. Também se utilizou como referência a marca líder de mercado no segmento de utensílios domésticos.

\subsection{Definição do conceito inicial}

A partir dos critérios definidos com as análises do briefing, do produto e de similares, foram geradas diversas ideias que foram resumidas em três principais. Estas foram estudadas pela equipe de projeto em relação à adequação aos aspectos técnicos e tecnológicos de produção, assim como ao portfólio da empresa. A partir deste estudo, uma ideia foi definida como conceito a ser explorado. A Figura 1 apresenta a opção selecionada que pode ser descrita como um suporte de produtos para box de banheiro.

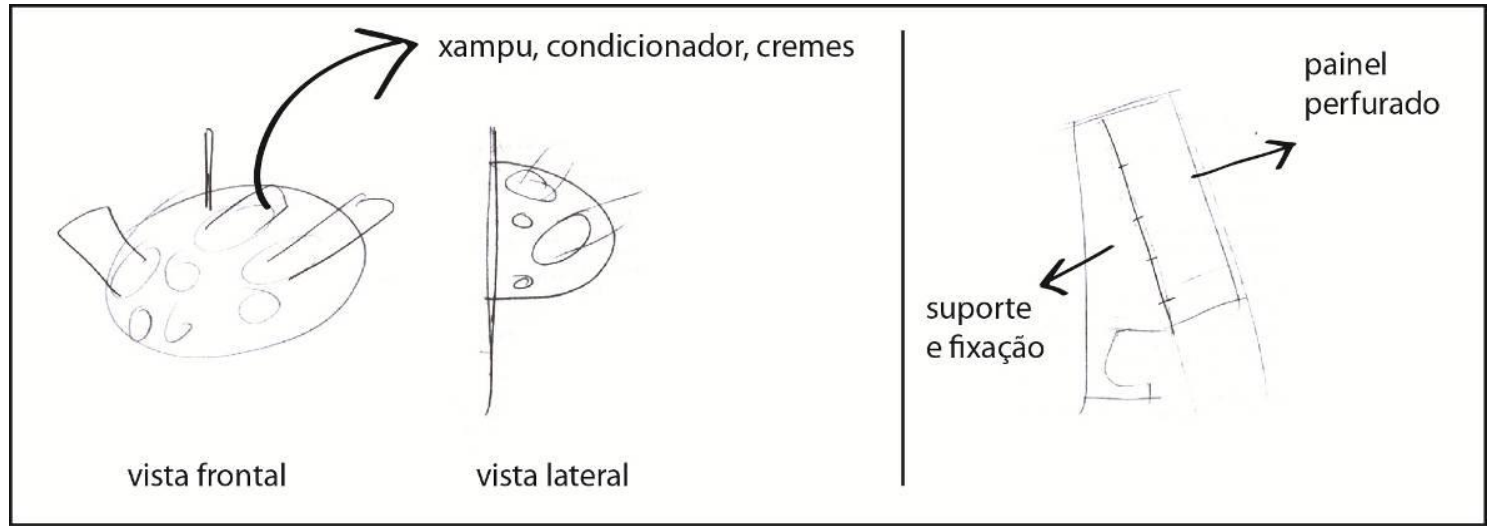

Figura 1 - Ideia inicial para o redesign de produto.

Fonte: Elaborado pelos autores, com base na pesquisa realizada.

\subsection{Modelagem digital parametrizada}

Este tópico apresenta a transição da ideia ao conceito do produto. Assim, o mesmo pode ser visualizado no mundo virtual e suas propriedades passam a ser percebidas pela equipe de projeto. Utilizou-se o processo de modelagem digital 
parametrizada por meio dos softwares Rhinoceros ${ }^{\circledR}$ e Solid Edge ${ }^{\circledR}$. A modelagem dividiu-se em duas etapas principais: modelagem e exploração do conceito de produto; e definição e preparação para produção do protótipo.

A primeira etapa do processo de modelagem do produto define a forma geral do conceito. Para isso, utilizou-se o software Rhinoceros ${ }^{\circledR}$ auxiliado pelo plugin Grasshopper ${ }^{\circledR}$. Com esta combinação foi possível modelar os principais parâmetros da forma do produto como módulos principais, espessuras e encaixes, sendo possível alterá-los e visualizá-los em tempo real.

O Grasshopper ${ }^{\circledR}$ permite realizar a modelagem tridimensional de objetos por meio de uma linguagem de programação gráfica. Ao invés das linhas de códigos textuais utilizadas em linguagens de programação tradicionais, a lógica é construída com a adição de elementos gráficos como boxes ou planilhas, que cumprem funções distintas e são interligados com conectores. As diferentes funções levam à operações de modelagem 3D e podem ser controladas por elementos chamados de sliders. Estes assumem um valor numérico e podem corresponder a parâmetros de projeto como tamanho total, distância entre elementos, ângulos, espessuras, quantidade de peças, entre outros.

O conceito do produto foi constituído de dois elementos: a base, que é responsável pela sustentação e fixação do produto; e um painel perfurado, que permite o encaixe dos acessórios de banheiro. $O$ código de programação desenvolvido para gerar o modelo 3D do conceito de produto se divide em três partes principais: i) o perfil do produto; ii) o trilho que percorre o perfil; iii) a junção das duas partes e o painel que suporta os acessórios de banheiro. A Figura 2 apresenta uma visão geral do código desenvolvido.

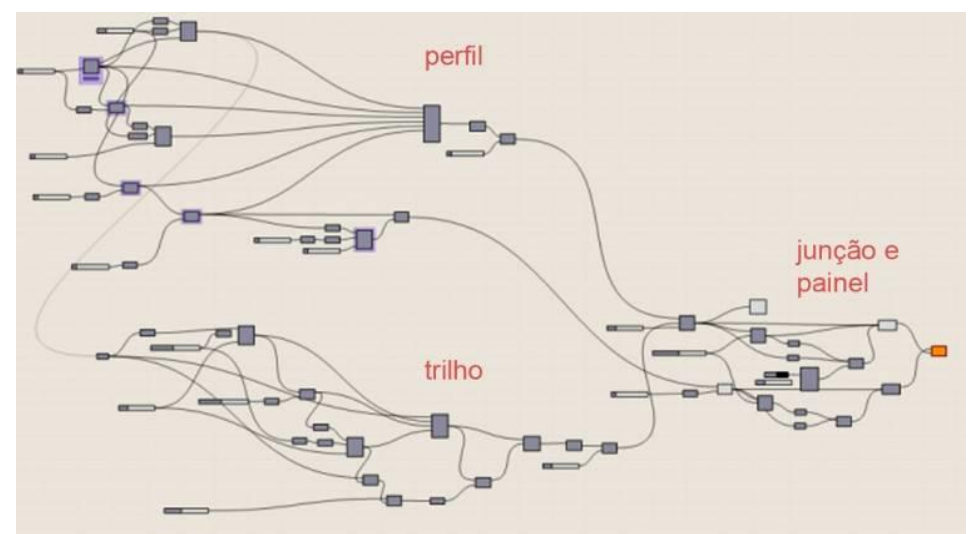

Figura 2 - Programação no Grasshopper ${ }^{\circledR}$.

Fonte: Elaborado pelos autores, com base na pesquisa realizada.

A partir das medidas determinadas para o produto na ideia inicial, foram definidos os pontos de controle no espaço tridimensional para formar o perfil do produto. Esses pontos podem ser controlados pelos sliders e correspondem aos parâmetros de altura total, altura da saboneteira, distâncias entre pontos, angulação da saboneteira e angulação e altura total do painel perfurado. A Figura 3 apresenta a interface do Grasshopper ${ }^{\circledR}$ e duas variações de concepção geradas considerando os parâmetros citados. O retângulo verde corresponde ao slider que controla o ângulo de inclinação da saboneteira. 

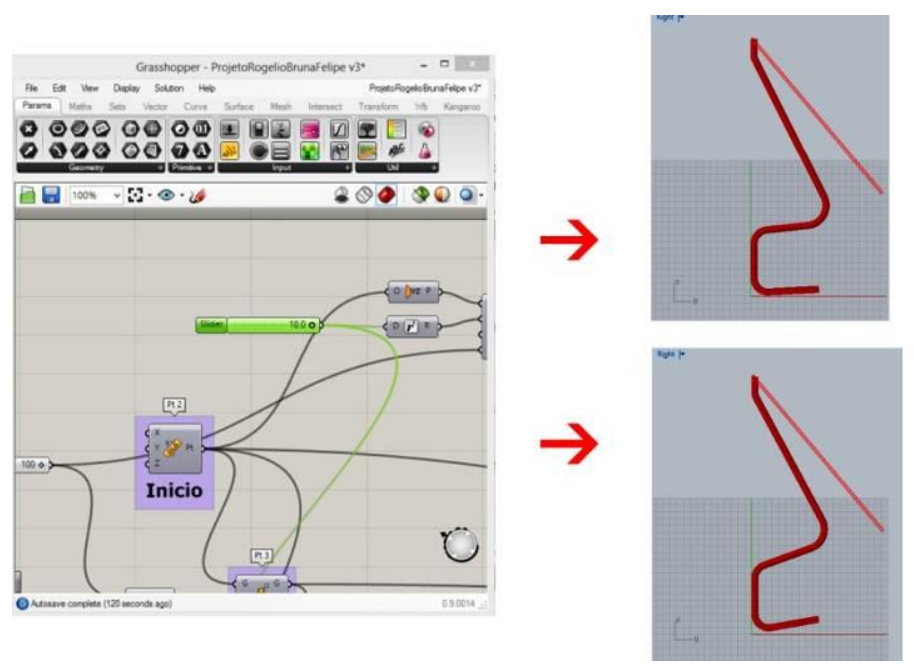

Figura 3 - Variações no perfil do modelo 3D.

Fonte: Elaborado pelos autores, com base na pesquisa realizada.

O trilho do modelo 3D - a linha que perpassa o perfil do modelo - também pode ser controlado por sliders. Nesse caso, os parâmetros manipuláveis correspondem à largura total do produto, à altura e à largura das canaletas que provêm a sustentação do produto, assim como, sua angulação em relação ao eixo horizontal. A Figura 4 apresenta os sliders de controle e duas concepções geradas com variações nos parâmetros referidos.
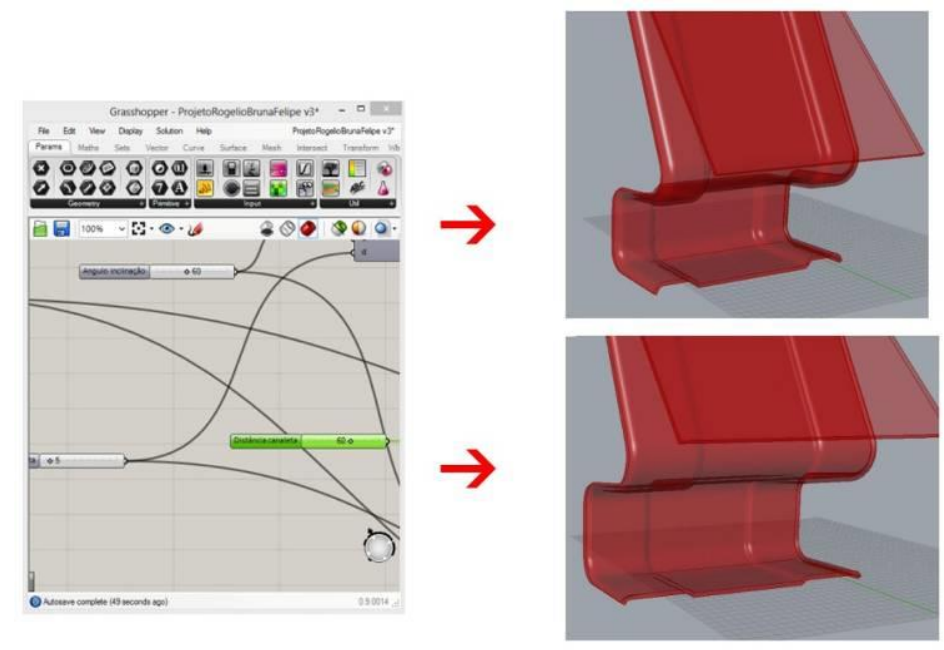

Figura 4 - Variações no trilho do modelo 3D.

Fonte: Elaborado pelos autores, com base na pesquisa realizada.

Após testar diferentes possibilidades de configurações formais com o uso do Grasshopper $^{\circledast}$, chegou-se ao modelo de produto apresentado na Figura 5. As opções foram avaliadas considerando aspectos funcionais, estruturais e estéticos do produto, assim como os critérios de design definidos pelas análises realizadas.

Podem-se ressaltar alguns pontos para a compreensão do produto: a parte inferior, dedicada a acomodar o sabonete, possui um ângulo que evita a queda do sabonete e escoa a água através de furos nesta parte; sua altura permite ao usuário pegar o sabonete com conforto e segurança, evitando quedas; o painel superior que suporta os xampus e outros acessórios tem uma inclinação que permite alocar 
acessórios menores na parte superior e acessórios maiores na parte inferior; as canaletas possuem dupla função: aumentar a sustentação da peça injetada com polímero e fornecer suporte ao sabonete e às placas que apoiam os acessórios.

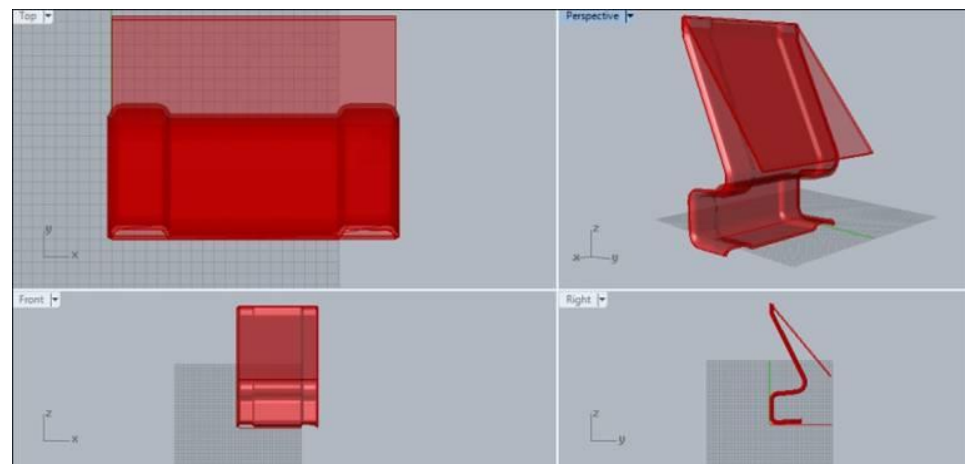

Figura 5 - Conceito de produto definido no Grasshopper ${ }^{\circledR}$

Fonte: Elaborado pelos autores, com base na pesquisa realizada

O desenvolvimento do modelo 3D no Grasshopper $^{\circledR}$ foi eficiente para gerar variações a partir de uma concepção, porém tornou-se complexo para fins de detalhamento da solução final. Dedicou-se tempo extra para definir os encaixes entre as duas peças sem sucesso. Portanto, a finalização do modelo e o detalhamento do produto ocorreram no software Solid Edge ${ }^{\circledR}$.

$\mathrm{Na}$ segunda etapa da modelagem do produto, o modelo 3D foi exportado em formato STEP (Standard for The Exchange of Product model data), padrão para troca de informações entre softwares CAD, conforme a norma ISO 10303 (PRATT, 2001). A partir disso, realizou-se o refinamento no modelo 3D, definindo-se raios, encaixes e demais detalhes necessários para adequar o produto para à fabricação por meio de injeção em polímero.

A Figura 6 apresenta o detalhamento do produto com as cotas exibidas em milímetros. $O$ ângulo de inclinação da placa frontal foi definido em $40^{\circ}$ para propiciar o encaixe e a fixação dos produtos.
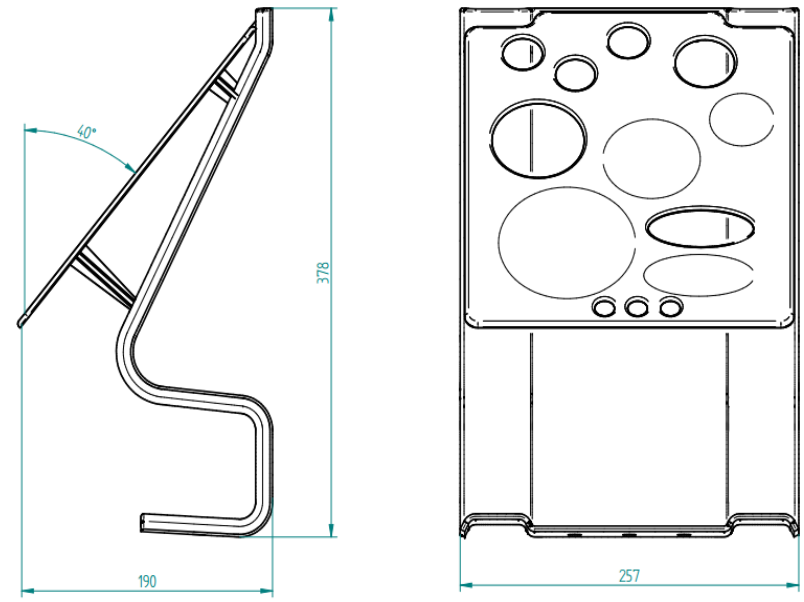

Figura 6 - Detalhamento do produto.

Fonte: Elaborado pelos autores, com base na pesquisa realizada. 


\subsection{Prototipagem digital}

A prototipagem digital permite realizar simulações e testes no meio digital para auxiliar no processo de desenvolvimento de produto. A seguir são apresentados alguns testes realizados objetivando visualizar as opções de cores, o encaixe de objetos no produto, e o comportamento do produto em um ambiente real.

A Figura 7 mostra aplicações de cores sobre o produto. A paleta de cores foi retirada do portfólio da empresa, considerando a linha de produtos ao qual este pertence.

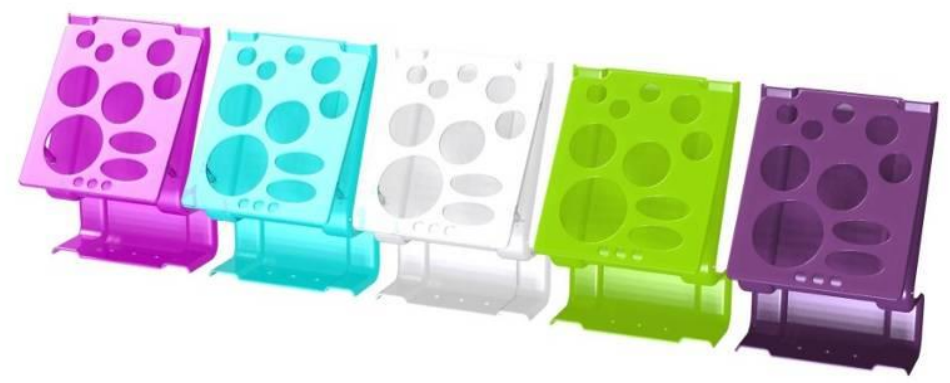

Figura 7 - Padrões de cores da empresa.

Fonte: Elaborado pelos autores, com base na pesquisa realizada.

A Figura 8 apresenta a simulação do produto em uma situação real de uso, considerando os diferentes objetos encaixados no mesmo. Nesta figura percebe-se que a solução desenvolvida comporta objetos variados de tamanhos distintos.

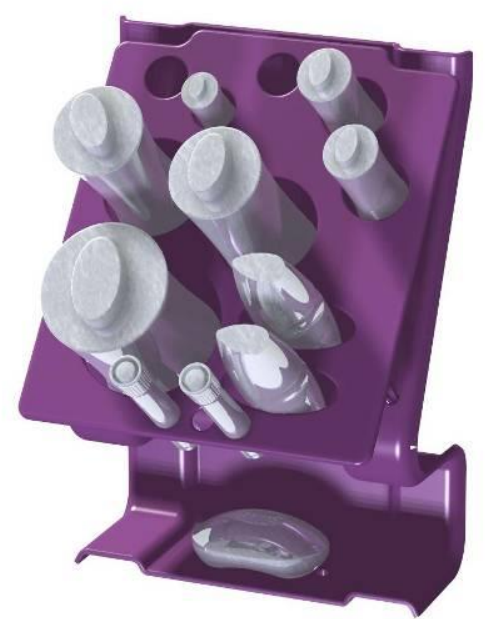

Figura 8 - Modelo com produtos de higiene.

Fonte: Elaborado pelos autores, com base na pesquisa realizada.

A fim de verificar se as dimensões do produto estariam de acordo com o seu local de uso, o modelo 3D foi inserido em um ambiente simulado de box de banheiro (Figura 9). Esse teste serviu também para especificar a altura do produto em relação ao solo, definida em 1,10 metros. 


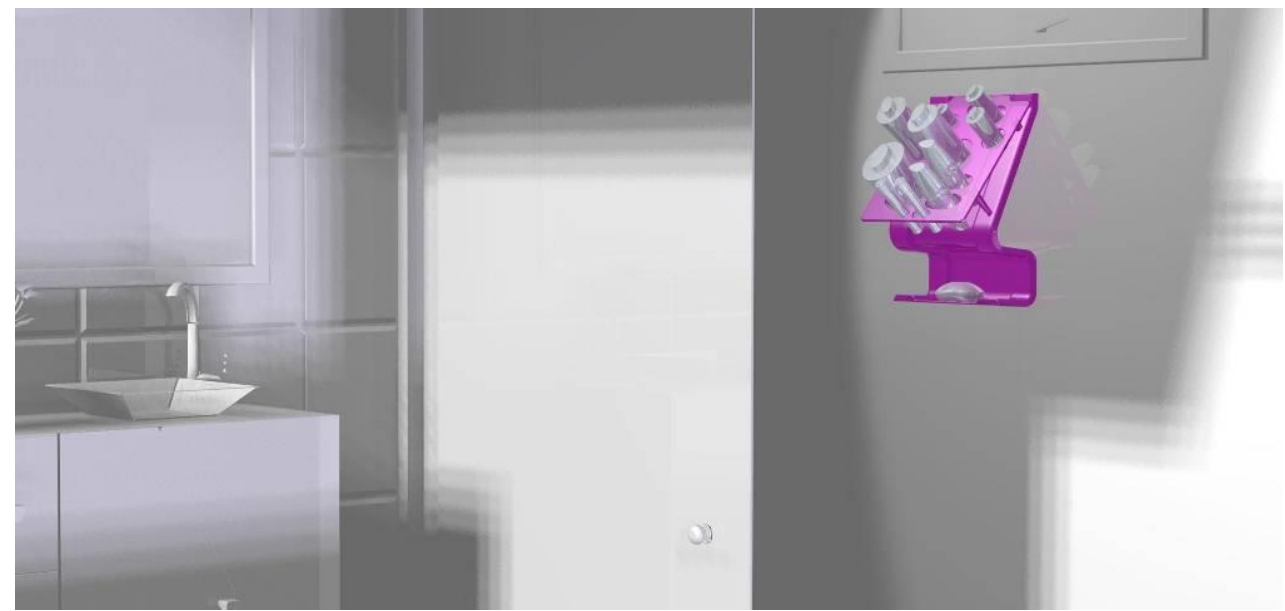

Figura 9 - Simulação do produto em uso.

Fonte: Elaborado pelos autores, com base na pesquisa realizada.

\subsection{Fabricação do protótipo e prototipagem física}

Devido a inviabilidade de fabricação de um protótipo físico em polímero injetado ou produzido via impressora 3D, em função do alto custo de seus respectivos processos, a equipe de projeto realizou adaptações no modelo 3D para possibilitar a produção de um protótipo de testes. Esta adaptação foi realizada levando em conta o processo de fabricação digital de corte a laser CNC.

No modelo adaptado, a solução desenvolvida anteriormente em duas peças passou a ser constituída de múltiplas peças planas. A Figura 10 apresenta o modelo adaptado para a fabricação digital em roxo e a solução original em amarelo. Devido ao novo sistema estrutural, o produto teve algumas dimensões alteradas, caracterizando um protótipo de baixa fidelidade.
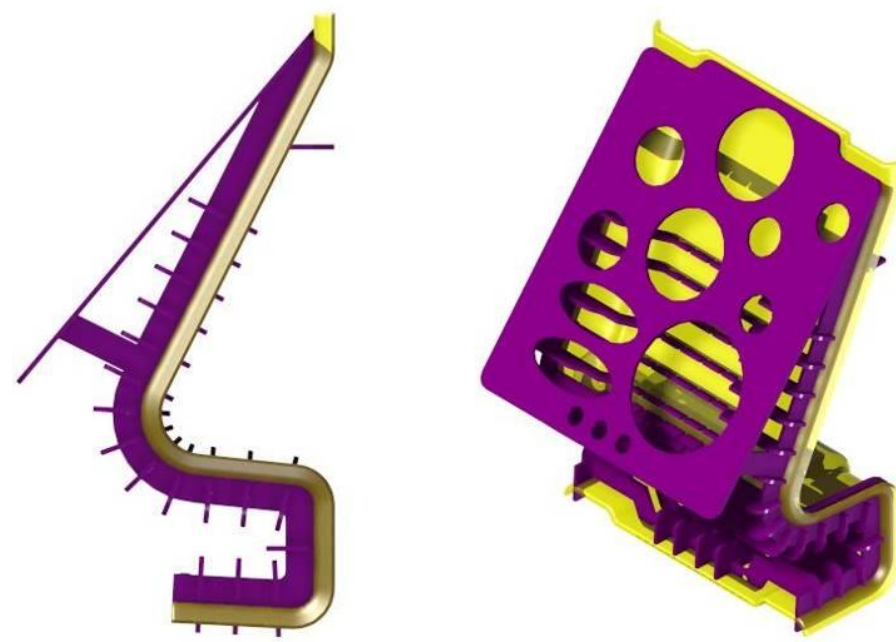

Figura 10 - Modelo adaptado para a fabricação digital de corte laser.

Fonte: Elaborado pelos autores, com base na pesquisa realizada.

Para a produção do protótipo, todas as peças do modelo 3D foram exportadas em um arquivo DXF e realizou-se a programação do corte no software SmartCarve ${ }^{\circledR}$. 0 corte das camadas foi executado em acrílico de $5 \mathrm{~mm}$ para as peças principais e $3 \mathrm{~mm}$ para as chapas de reforço na máquina de corte laser Yueming CMA-1200 (Figura 11). Depois de cortadas, as peças foram coladas com o adesivo instantâneo Super Bonder ${ }^{\circledR}$. 
O posicionamento das peças estruturais havia sido previsto através de encaixes nas peças principais.

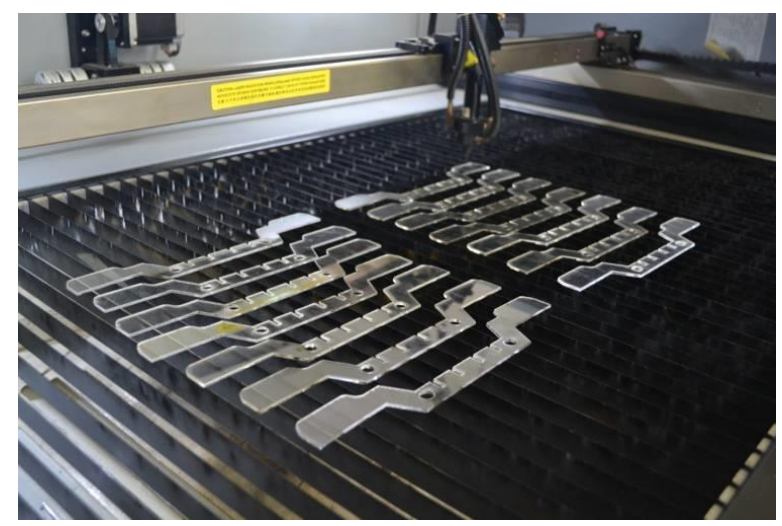

Figura 11 - Peças cortadas na máquina a laser.

Fonte: Elaborado pelos autores, com base na pesquisa realizada.

O protótipo físico construído em escala real foi utilizado para testes com o usuário e verificação de requisitos de projeto. O protótipo de baixa fidelidade serviu para testar aspectos funcionais do produto, sendo realizados testes ergonômicos com um usuário. A Figura 12 apresenta o usuário encaixando um xampu no produto e simulando a pega do sabonete.
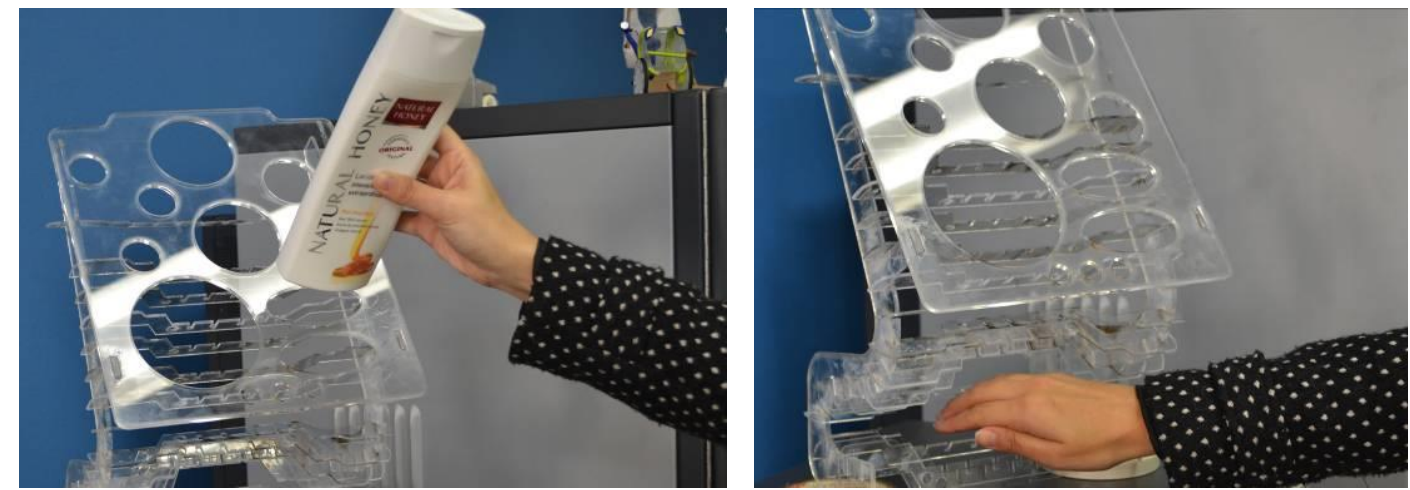

Figura 11 - Protótipo físico.

Fonte: Elaborado pelos autores, com base na pesquisa realizada.

Verificou-se, a partir dos testes realizados, que as medidas gerais do produto, como a altura total, a largura e a altura do reservatório para o sabonete estão adequadas. O usuário foi capaz de executar um fluxo de tarefas determinados sem dificuldades. A inclinação do painel perfurado foi considerada adequada para o manuseio do produto. Por outro lado, as medidas e os furos no painel devem ser redimensionados, pois dos seis produtos testados apenas dois se encaixaram. Constatou-se que a elipse é um formato mais restrito, sendo que o círculo suportou um número maior de acessórios.

\section{CONCLUSÃO}

O software Grasshopper ${ }^{\circledR}$ demonstra-se uma ferramenta eficaz para gerar diversas variações de concepções de produtos a partir de uma alternativa. Uma das grandes vantagens percebidas ao utilizar o Grasshopper ${ }^{\circledR}$ na prototipagem 3D de produtos é a possibilidade que fornece de variação nos parâmetros de projeto em tempo real. 
Dessa forma, pode-se gerar variações em uma concepção de produto de maneira automatizada e simples, sem a necessidade de remodelar o protótipo virtual do produto. Entretanto, o software possui limitações em ajustes finos no modelo tridimensional, podendo vir a ser substituído por outro software na etapa de detalhamento de projeto.

Os métodos de prototipagem digital e físico são complementares e podem ser executados em paralelo com o desenvolvimento do projeto. O protótipo digital, construído em softwares CAD e fiel a solução final, permitiu realizar a comunicação eficaz do produto considerando os stakeholders. O produto foi simulado utilizando cores contidas no portfólio de produtos da empresa em um contexto de uso real.

A construção do protótipo físico em tamanho real permitiu verificar questões ergonômicas e funcionais, como o encaixe e desencaixe dos acessórios de banheiro e o tamanho do produto em relação ao usuário. Os ajustes efetuados no modelo 3D para possibilitar a fabricação digital do protótipo modificaram alguns aspectos do produto, entretanto, foi possível realizar os testes citados com o usuário, auxiliando no processo de projeto.

A partir da prototipagem física por meio de processos de fabricação digital, ficaram evidentes alguns ajustes necessários para atender os requisitos de projeto. Dessa forma, a prototipagem física se mostra um método eficaz para auxiliar no desenvolvimento de produtos.

\section{REFERÊNCIAS}

ASHBY, M., JOHNSON, K. Materiais e design: arte e ciência da seleção de materiais no design de produto. Rio de Janeiro: Elsevier, 2011.

BACK, N. et al. Projeto integrado de produtos: planejamento, concepção e modelagem. Barueri: Manole, 2008.

BOLGENBAGEN, N. O Processo de Desenvolvimento de Produtos: Proposição de um Modelo de Gestão e Organização. Dissertação de Mestrado UFRGS, Porto Alegre, 2003. ESPINOZA, M.; SCAEFFER, L. Uso do CAD/CAE/CAM na Produção de Matrizes para Processos Novos de Conformação Mecanica. Revista del Instituto de Investigación FIGMMG, v. 7, n. 14, p. 84-91, 2004.

HALLGRIMSON, B. Prototyping and modelmaking for product design. London: Laurence King, 2012.

ORCIUOLI, A. O impacto das tecnologias de fabricação digital nos processos de design. Arquitetura e Urbanismo, v. 183, jun. 2009. Disponível em: $<$ http://www.revistaau.com.br/arquitetura-urbanismo/183/o-impacto-dastecnologias-de-fabricacao-digital-nos-processos-de-141180-1.asp>. Acesso em: 20 jul. 2013.

PAHL, G. et al. Projeto na Engenharia: Fundamentos do Desenvolvimento Eficaz de Produtos, Métodos e Aplicações. São Paulo: Edgard Blucher, 2005.

PRATT, M. Introduction to ISO 10303 - the STEP standard for product data exchange. Journal of Computing and Information Science in Engineering, v. 1, n. 1, p. 102-103, 2001.

SLACK N.; CHAMBERS S.; JOHNSTON R. Administração de Produção. 3. ed. São Paulo: Atlas, 2007. 